\title{
CATEDRAL DE PRESIDENTE PRUDENTE: UM PATRIMONIO ARQUITETÔNICO
}

\author{
Beatriz Minatti, Cláudia Sawada, Fabrícia Dias da Cunha de Moraes Fernandes Borges
}

Universidade do Oeste Paulista - UNOESTE, Curso de Arquitetura e Urbanismo, Presidente Prudente, SP. E-mail: fabricia.arquiteta@gmail.com

\section{RESUMO}

O presente artigo tem como objetivo mostrar a evolução arquitetônica e a história da Igreja Matriz de Presidente Prudente, conhecida como Catedral, a Paróquia de São Sebastião pertencente a diocese de Presidente Prudente, revelando fatos históricos como seus construtores, os interesses e percepções atuais sobre sua arquitetura e preservação, sobretudo, apontando as datas de lançamento da pedra fundamental, reformas, tombamento e destombamento, contando a história desde a vontade da construção de uma igreja que fosse a representatividade da cidade até a situação nos dias atuais, utilizando de fontes datadas e seguras. Tem-se a intenção da elaboração do inventário de bens culturais, contendo informações do projeto da igreja, sua execução, as doações para sua construção. A partir disso, é possível também conhecer sobre sua filiação arquitetônica, além do seu impacto direto no desenvolvimento da cidade.

Palavras-chave: Igreja, Presidente Prudente, art decó, restaurações, inventário.

\section{CATEDRAL IN PRESIDENTE PRUDENTE: AN ARCHITECTURAL HERITAGE}

\begin{abstract}
This paper has the objective to show the architectural evolution and the history of the one Church in Presidente Prudente, known as the Cathedral, the Parish of San Sebastian belonging to the Diocese of Presidente Prudente. Aspects of historical facts as its builders, interests and current perceptions its architecture and preservation, especially pointing out the release dates of the cornerstone, reforms, tipping and unlisted as a historical site are important, and they tell us the story from the will of the construction of a church that was the representation of the city to the situation today, using dated sources and secure. There is the intention of establishing the inventory of cultural property, containing the church project information, implementation, donations for its construction. Thus, it is also possible to know about its architectural affiliation, beyond their direct impact on the development of the city.
\end{abstract}

Keywords: Church, Presidente Prudente, art decó, restorations, inventory. 
INTRODUÇÃO

A história da cidade de Presidente Prudente se inicia com a chegada da ferrovia, facilitando o transporte de mercadorias no Oeste Paulista, principalmente do café. O Coronel Francisco de Paula Goulart, juntamente com seus irmãos, fundaram a vila Goulart que abrangia vários loteamentos, a fim de trazer população para a cidade para trabalhar em suas plantações de café. Além de Goulart, do outro lado da cidade se fixou o Coronel José Soares Marcondes que possuía uma empresa para vendas de terras. A cultura do café era a atividade econômica mais importante para o município, com o crescimento econômico, muitos imigrantes chegam a cidade na intenção de constituir uma família e uma vida na cidade. Com o crescimento populacional, precisou-se da criação do primeiro grupo escolar do município, a Escola Estadual Professor Adolpho Arruda Mello, uma Casa de Saúde, Delegacia de Ensino, dentre outras, e com a chegada do Bispo, foi planejada e construída a Igreja Matriz da cidade, conhecida como Igreja São Sebastião, Catedral, e a partir dela, o desenvolvimento do centro da cidade se deu ao seu redor e após alguns anos a cidade já havia se tornado político e economicamente autônoma e a maior cidade da região.

\section{METODOLOGIA}

Pesquisa realizada na intenção de começar o processo de inventário da Igreja de Presidente Prudente. Foram realizados estudos in loco, em bibliotecas, com intenção de entender cronologicamente os fatos, e conhecer a história da construção da Igreja para analisar sua forma e estilo e comparar com os dias de hoje verificando as mudanças ocorridas ao longo dos anos. Através deste estudo aprofundado, formatou-se o inventário na intenção de tornar a Igreja um patrimônio cultural da cidade.

\section{DADOS HISTÓRICOS}

A Catedral é a principal Igreja da cidade, pois foi ao redor dela que a cidade se desenvolveu. A cidade antes da Igreja era praticamente rural, poucas casas construídas, com predominância do verde. Quando foi construída, sua grandiosidade chamou atenção aos habitantes e por ter sido a primeira Igreja construída na cidade, serviu de referência para outras construções.

O primeiro projeto da igreja é datado dia 21 de Julho de 1927 e sua construção começou em meados do ano de 1949. Anteriormente, o que existia na cidade era apenas uma capela (FIGURA 01), construída no ano de 1918, feita de madeira a mando do fundador da cidade José de 
Paula Goulart e executada pelo carpinteiro Sebastião Parque Rosillo. A ideia da construção de uma nova igreja para a cidade chegou junto com o Padre José Maria Martinez Sarrion em 1925, que gostaria que a igreja fosse um marco para a cidade que possuía o crescimento mais promissor da Alta Sorocabana, conta Benjamin RESENDE (2006, p. 203) em seu livro:

[...] exigiu de si a construção de uma igreja, que fosse a representatividade da cidade que mais crescia na Alta Sorocabana. Não dimensionava sua aspiração. A obra tinha que nascer. $O$ sonho tinha que se transformar em realidade. Não havia impossibilidade. Sua vontade estava além do destino e de Deus. A matriz haveria de ser o símbolo da cidade e da região [...]

Em 1927, o Padre José Maria criou uma comissão na tentativa de arrecadar fundos para a construção de uma igreja maior que fosse a representatividade da cidade, formada por membros das famílias de destaque na época: Armelin, Tenório de Barros, Peretti, Toledo, Franco de Godoy e outras.

O Bispo D. Carlos Duarte Costa participou do lançamento da pedra fundamental da Igreja Matriz provisória em 21 de julho de 1927. A planta da Igreja (FIGURA 02) foi feita por Francisco Oroz, a construção dirigida e executada por Francisco Grotto e idealizada por Luiz Mesquita. As obras iniciaram dois anos depois de formada a comissão.A Igreja Matriz definitiva teve sua pedra fundamental lançada em 04 de agosto de 1936. A torre (FIGURA 03) foi elaborada por Gotthard Kunsli do escritório do engenheiro Luiz Ferra de Mesquita e finalizada na década de 1940.

A antiga capela situava-se no lugar da atual fonte luminosa, terreno em frente da igreja matriz, por esse motivo, Francisco de Paula Goulart, doou o terreno para construção do templo, assim como a mesa de comunhão e os degraus das escadas que levam à capela-mor e a sacristia da igreja. Tannel Abbud comprou o relógio que continua originalmente exposto e ativo no ápice do templo ainda nos dias atuais e Felício Tarabay custeou o altar-mor, produzido com mármore.

Concluída em 1949, a Igreja tornou-se orgulho da cidade e ponto referencial (FIGURA 04).No dia 22 de setembro de 1950, foi inaugurada a Igreja Matriz pelo Monsenhor Sarrion que completava 50 anos de ordenação sacerdotal.Benjamin RESENDE (2006, p. 204) cita em seu livro este fato:

[...] Dia solene para todos os prudentinos, que recebiam do seu pároco o maior presente: uma igreja ampla, de estilo inconfundível, gigantesca para a época, mas que representava a grandeza do povo, aqui radicado, com todos os matizes de raças e esperanças. Do sonho de 1925, passado peto ato público de inauguração, em 1950, confirmando-se Catedral em 1960, com a criação da Diocese, eis a Catedral de São Sebastião altaneira e baliza da história de Presidente Prudente. Jamais ruirá. [...] 
Sua filiação estilística vem do movimento Art Decô, estilo influente na época. Fortes elementos explicam o estilo, como a valorização da entrada, formas geométricas, composição simétrica, pouca ornamentação, simetria apesar da torre mais alta não estar no centro da fachada, escalonamento da torre com base, corpo e coroamento.O desenho da planta é em forma de cruz, o corpo principal da nave, mede 13,5 metros e a nave inteira 58,5 metros. A torre tem altura de 42 metros e o restante da construção possui 24 metros de altura.

Em 1983, foi construído, em volta da Igreja, o estacionamento. Neste mesmo ano, a igreja foi tombada pelo CONDEPHAT (Conselho de Defesa do Patrimônio Histórico, Artístico e Turístico) como patrimônio da cidade, sofrendo uma reforma no ano de 1986 devido ao seu tombamento, havendo posteriormente apenas restaurações.

A Catedral passou por reforma, começando os trabalhos no dia 08 de Julho de 1986, realizado pela Prudenco, empresa responsável pela implementação da política de limpeza e obras públicas do município, que trocou o madeirame do telhado, suas telhas, os condutores de águas pluviais, refez a pintura externa de cor amarelo pastel. O engenheiro responsável pela reforma foi Paulo Machado Vasconcelos. Na edificação da Catedral, foram assentados 1.145 .000 tijolos, o investimento para a reforma foi de 400 mil cruzados, como mostra uma matéria do jornal 0 Imparcial, encontrado nos arquivos da biblioteca municipal de Presidente Prudente.

A prefeitura está investindo 400 mil cruzados na obra que além destes serviços da primeira etapa, prevê a troca de todo o piso interno da igreja, dos vitrais e vidros, restauração do altar e outras dependências da Catedral. (O IMPARCIAL, 1986)

A segunda parte da reforma não foi realizada pela prefeitura, ocasionando cobranças por parte da Igreja, pelo Bispo, que cobrava a troca do piso e a restauração da pintura interna da Igreja. O não cumprimento da promessa de reforma por parte da prefeitura de acordo com as exigências do Condephat e as cobranças do Bispo, acarretou em discórdia, ocorrendo o pedido de destombamento para que a Igreja assumisse a reforma, pois o imóvel tombado era de responsabilidade da prefeitura. O destombamento aconteceu no ano de 1993, pelo prefeito da época Agripino Lima, conta Hirao em um de seus trabalhos.

[...] foi destombado em 18 de outubro de 1993, sancionado Prefeito Agripino de Oliveira Lima Filho pela Lei №. 3.778/93 e apoiado pelo Bispo diocesano, Antônio Augusto Marochi. (HIRAO, 2012)

Após o destombamento, a Igreja assumiu a reforma, trocando todo o piso e restaurou toda a pintura interna. A restauração desta pintura pela última vez foi realizada em 1999, pelo artista 
plástico José Botosso. Segundo entrevista feita pela tv local da cidade, Botosso fala sobre esta experiência:

"Para mim foi um desafio pintar tudo isso. A tela é um espaço menor, não tem perspectiva e aquele visual de longe. É bem trabalhoso." (IFronteira, 2012)

Foram restauradas as pinturas de santos em todas as paredes internas, inclusive no teto (FIGURAS 05 E 06), ao todo foram 47 painéis restaurados.

\section{DADOS GERAIS}

Informações relevantes sobre as modificações ao longo dos anos da Igreja, suas reformas e restaurações, características, o que há em seu entorno, ou seja, fatores que fazem a Igreja ser como está hoje em dia.

\subsection{PRÁTICAS IMATERIAIS}

A partir da década de 1980, começou a ocorrer práticas imateriais em frente à Igreja, como procissões e missas campais em datas especiais, além de vendedores de frutas, pipoqueiros, garapeiros, onde alguns permanecem no local até os dias de hoje. Além disso, o local também possui pontos de ônibus que possuem total importância, pois de lá, transportam pessoas para todo o perímetro da cidade.

\subsection{SITUAÇÃO AMBIÊNCIA}

A Catedral se localiza na praça Monsenhor Sarrion, entre a Avenida Coronel José Soares Marcondes e as ruas Barão do Rio Branco, Ribeiro de Barros e Tenente Nicolau Maffei. Possui grande importância para a cidade pois foi ao redor dela que a cidade cresceu, ela leva o nome do padroeiro da cidade, e é considerada um ponto referencial da cidade, sua grandeza se destaca dos demais edifícios por estar no meio de uma praça rodeada por vegetação (FIGURA 07). A Igreja é conhecida regionalmente. Possui ao seu redor um estacionamento privativo, ambulantes, pontos de ônibus, ponto de táxi, além da livraria diocesana.

\subsection{DESCRIÇÃO ATUAL}

A Igreja possui uma relação direta com o espaço público, onde os pedestres transitam pelo sítio físico, sem nenhum impedimento, pois não há portões, muros ou barreiras, apenas as portas de acesso da Igreja que permanecem abertas durante todo o dia. O recuo existente se justifica por estar situada no centro da praça e não haver mais nenhuma edificação na mesma. Possui um pé 
direito principal de 24 metros, além de um pavimento inferior onde se localiza a livraria diocesana. As paredes são de alvenaria, externamente pintadas hoje com as cores palha, areia e concreto, com detalhes de pedras feitas no próprio concreto. Seu calçamento é asfaltado facilitando a movimentação dos carros no estacionamento. Há áreas que possuem gramado que são onde estão plantadas as árvores. As portas são de madeira e as janelas são vitrais com esquadria metálica. A circulação interna é horizontal, sua planta tem formato de cruz, com uma nave principal e duas secundárias. O acesso público da Igreja se dá pelas portas laterais e frontal. Internamente, a Igreja possui vários painéis com temas bíblicos nas paredes e no teto, o piso interno é de porcelanato, a Igreja ainda possui no seu interior detalhes em madeira (FIGURA 08) e altar de mármore. Externamente a Igreja não possui revestimentos. Sua cobertura é de telhado de duas águas.

\section{ESTADO DE CONSERVAÇÃO E PATOLOGIAS}

A Igreja está muito bem conservada, possuindo apenas algumas goteiras e pinturas descascadas. Percebe-se que não há presença de manchas escuras nem na fachada e nem no interior. O piso está extremamente conservado. A Igreja é cuidada todos os dias por funcionários responsáveis pela limpeza e conservação geral, evitando qualquer dano maior. No seu exterior, há pequenas pichações em algumas partes das paredes.

As alterações realizadas ao longo dos anos não modificaram a planta original da Igreja, só houveram reformas pequenas e restaurações de pinturas internas e externas, não prejudicando o seu valor estético.

\section{FOTOGRAFIAS E PEÇAS GRÁFICAS}

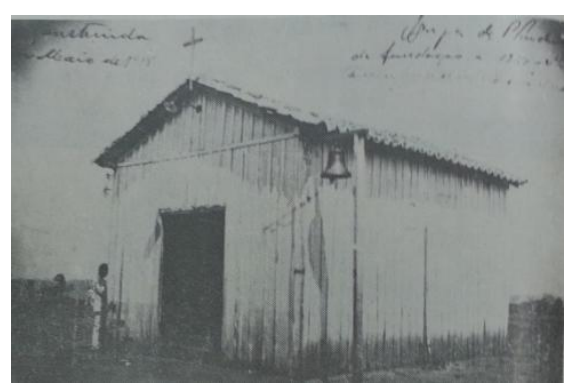

Figura 01. Primeira Capela

Fonte: (Abreu, 1925)

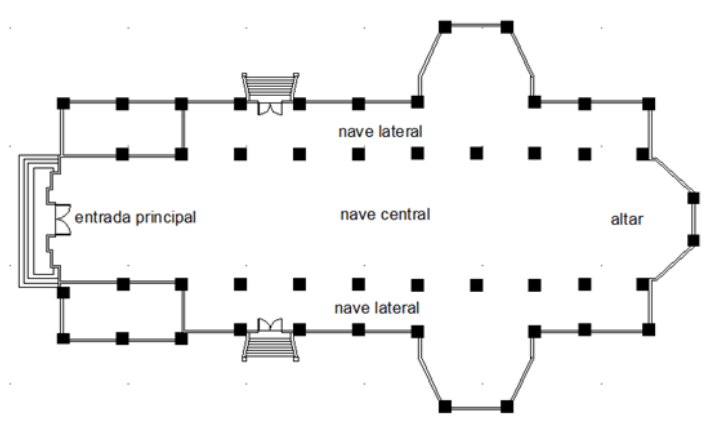

Figura 02. Planta Baixa

Fonte: (da equipe, 2015) 


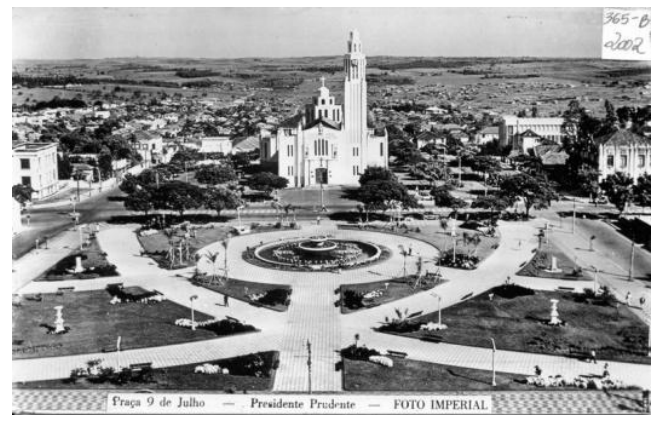

Figura 03. Monumento da cidade

Fonte ( Foto Imperial, 1952)

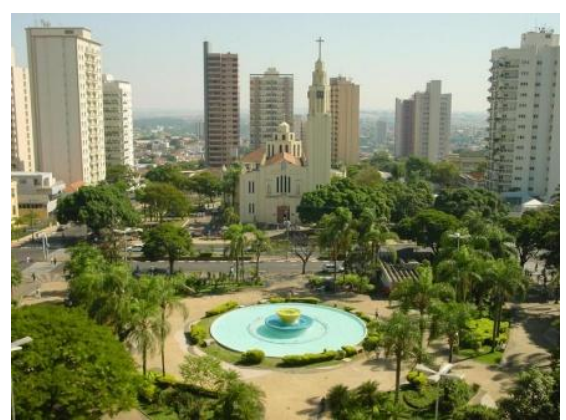

Figura 04. Praça rodeada pela vegetação

Fonte: ( Ifronteira, 2003)

\section{CONCLUSÕES FINAIS}

A partir deste estudo foi possível notar a importância da igreja no desenvolvimento de uma cidade. A construção da Catedral influenciou diretamente no desenvolvimento da cidade de Presidente Prudente, que cresceu a partir da igreja. Através das imagens é possível visualizar o desenvolvimento da cidade em torno da igreja, onde na FIGURA 03 não existem altas edificações e a vegetação ainda é jovem, diferente da FIGURA 04, que as altas edificações criam um limite no horizonte e a vegetação esconde todo o entorno imediato à igreja. A memória cultural que a Catedral possui é de grande relevância para a história dos prudentinos.

\section{REFERÊNCIAS}

ABREU, Diores Santos. Formação Histórica De Uma Cidade Pioneira Paulista: Presidente Prudente. Faculdade de filosofia, ciências e letras de Presidente Prudente, p.189-192, 1972.

BARROS, Helena Faria de. "Bandeirante do Século XX" - Fundação de Presidente Prudente narrada pelo seu fundador. p. 24. 1917-1967

D'INCAO, Maria Angela. Presidente Prudente Capital Regional.2007.

EMUBRA. Vida Religiosa em Presidente Prudente. Publicado em: 2003. Disponível em: http://camarapprudente.sp.gov.br/historia/hist_oeste/cidades/pprudente/religiao.html. Acessado em: $27 / 05 / 2015$.

HIRAO, Hélio. O Patrimônio Arquitetônico e Urbanístico de Presidente Prudente: O Possível Preservado. Publicado em: $2012 . \quad$ Disponível em: http://revista.fct.unesp.br/index.php/topos/article/viewFile/2514/2247 . Acessado em Agosto de 2015.

IFRONTEIRA. Botosso, pintor da catedral de PP, morre após complicações de AVC. Publicado em: 09 de Abril de 2012. Disponível em: http://www.ifronteira.com/noticia-presidenteprudente-620 . Acessado em Maio de 2015. 
MUNICIPAL, Museu. Museu e Arquivo Histórico prefeito Antonio Sandoval Netto. Disponível em: http://museu.presidenteprudente.sp.gov.br/historiapp.php . Acessado em: Agosto de 2015.]

RESENDE, Benjamin. Raízes Prudentinas 2. 1a edição, p.203-204, 2006. 